\title{
An Appointment System in a Practice with Immigrant Patients.
}

\author{
STUART CARNE,* M.B., M.R.C.G.P., D.C.H.
}

In the group practice of which I am a partner patients have been seen by appointment for over six years. We adopted an appointment system when the two previously separate parts of the practice joined on 1 January 1962. It was essential to do something of this nature because of the shortage of space in the waiting-room. The premises now used by the group were those originally occupied by a single-handed general practitioner with a list of 1,600 patients. The space available was barely adequate for his needs. We were able to convert two rooms into extra consulting-rooms, so that at any one time three doctors can now consult, but there was no one room bigger than that used as the waiting-room. Unless we had two waiting-spaces, which would have been difficult to administer, we had no alternative but to restrict the number of patients waiting to be seen at any one time. In that the waiting-room, which has seats for only 12 people, has rarely been full to capacity, and patients no longer have to wait in the street outside; and in spite of there being three doctors, each seeing up to 12 patients an hour; and notwithstanding the fact that some patients (children always) come accompanied by at least one relative, the appointment system has worked.

I have described elsewhere the mechanics of our system of arranging appointments (Carne, 1963). We in our group believe that patients should, whenever possible, have choice of doctor. Even more important, we believe that one doctor should normally treat every member of each family. Most important of all, we aim to arrange our bookings so that each illness episode is dealt with by the same G.P. To assist the receptionists (we need two working full-time on a shift system plus a full-time secretary) we have colour-coded our appointment cards, and we colour-code the family medical record envelopes where one member of the group deals with their personal problems.

A high proportion of the patients in the practice are immigrants (Carne, 1967). Some of the social difficulties, with particular reference to the poverty of their housing, have been described elsewhere (Carne, 1962). It was therefore thought wonth while to study the utilization of an appointment system by such patients.

\section{Method}

From time to time we have attached to the practice pupils from West London College who are taking the medical secretary's course with the view of obtaining the diploma of the Association of Medical Secretaries. They come in turn for a week of practical experience. For one session during their week the girls from the 1966-7 course were asked to keep a note of the time of arrival, the time of the appointment, and the time the patient actually went into the doctor's consultingroom. One record card was kept for each consultation. As most patients had booked an appointment, and as the medical record envelopes for these patients together with the relevant sheet from the appointment book was available the day before the session, the girls were able to set up most of their study cards in advance. On each card they also put the code number we use for the practice, which enables us to identify the patient's

- General Practitioner, London W.12. age, sex, and race. ${ }^{1}$ At the end of the study the age, sex, and race groups were sorted by hand. It was then an easy task to determine how early or how late a patient arrived in relation to the time of his appointment (arrival time : appointment time) and how long each patient had to wait (arrival time: time of actual consultation).

\section{Findings}

Altogether there were records of 950 patients who had made appointments and were seen. In addition, there were 100 patients who had made appointments and failed to attend. There were also 98 patients who had not made an appointment but wished to see the doctor at the time they visited the surgery. It was (and still is) our practice to offer such patients an appointment either later at that consulting session or at another session." If the patients express a preference to be seen then and there they are invited to wait until there is a gap. If in the opinion of the receptionist they look ill or she thinks it unwise to keep them waiting-for example, some mothers still bring children with a rash to the surgery rather than call for a visit (Carne, 1967)-she will send them through to a doctor ahead of waiting patients who have an appointment. In the rare event of an emergency-for example, a child carried in from a street accident outside-she will even "buzz" one doctor on the intercom and ask him to clear his surgery at once. We rely very heavily on our receptionists for the success of the appointment system.

\section{Arrival and Waiting Times}

In Table I are given the waiting and arrival times for all the patients who attended by appointment, and the proportion for the different age, sex, and race groups.

There is hardly any difference in the waiting or arrival time between men and women.

Of all the patients who were seen by appointment $13.8 \%$ walked straight through to their doctor on arrival; the doctor was waiting for them. This is because we have always aimed to avoid overbooking. We believe that in general practice there cannot be a predetermined end to an ordinary consulting session. If 85 instead of the usual 75 patients need to be seen (or think they need to be seen) at one session then that session will take that much longer. What is possible-is to anticipate difficulties. For example, reappointments are kept to a minimum on Monday mornings; none at all are made for the individual doctor at any session if he wishes to finish earlyfor example, to go to the theatre. The effect of this is to even out some of the humps of an ordinary practice load, but not all. Because we do this, and because so many appointments are missed, there are gaps into which extra patients can be fitted and there are many times when the doctor has to wait for his

\footnotetext{
1 The code used is simple: the last two numbers of the year of birth ; 0 and 1 for male and female respectively; and 0-6 to describe the various race groups-for example, 46.1 .3 refers to a patient born in 1946, female, and West Indian.
} 
TaBle I.-Waiting and Arrival Times (Expressed as Percentages)

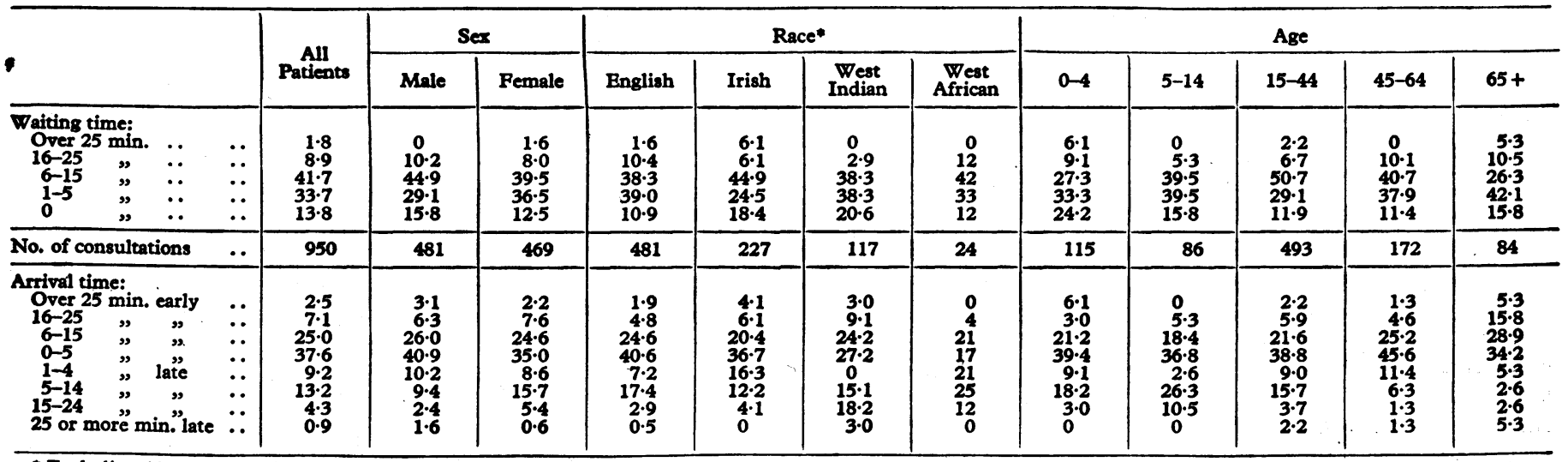

- Excluding 101 patients who did not come into the four groups listed.

next patient. We have discussed this among ourselves. We would rather have these gaps than revert to the pressures of a crowded waiting-room.

There is little difference between the English and Irish patients so far as waiting and arrival times are concerned; the English are a little bit better at arriving promptly. The West Indian patients, however, are not as good timekeepers. A larger proportion come much too early or come late for their appointment. On the other hand, for reasons discussed later, they tend to spend less time in the waiting-room. There were only 24 booked consultations with West African patients recorded for this study, and this number is too small for any valid conclusions to be drawn. If the sample is in any way representative the West Africans are the worst timekeepers of all.

Though there are differences in the waiting times of the patients of varying ages, none of these differences are significant. More children tend to arrive late than adults. The best timekeepers of all are the elderly. Only 20\% of the 45-64's come late and only $15 \%$ of the over 65 's. On the other hand, it should be noted that there are very few immigrants in these two older age groups (Carne, 1967).

The mean waiting time for all the patients is six to eight minutes. As we book two patients every 10 minutes, and are therefore expecting one to wait five minutes, this is about as optimal a degree of efficiency as we can hope for, though we would like to see the extremes reduced so far as is possible.

Fewer of our patients are punctual than the patients described by Bevan and Draper (1967) for the 10 practices they studied. Our practice has had an appointment system five years longer than any of those described in that study. On the other hand, far fewer of our patients wait more than 30 minutes, so that perhaps we have had time to get ourselves better organized. The waiting time is less than that found by Fry et al. (1963).

What are the patient's best chances of reducing his waiting time? Table II shows the waiting time in relation to the arrival time, from which it can be seen that the optimal time of arrival appears to be 15 to 24 minutes late ; $4.3 \%$ of all the patients chose such a time of arrival. It is certain that if the other patients also arrived as late the system would collapse. In

Table II.-Time Spent Walning by Patients in Relation to Time They Arrived Before or After the Scheduled Times of Appointment (Expressed as a Percentage)

\begin{tabular}{|c|c|c|c|c|c|c|c|c|}
\hline \multirow{3}{*}{$\begin{array}{l}\text { Waiting } \\
\text { Time }\end{array}$} & \multicolumn{8}{|c|}{ Arrival Time (minutes) } \\
\hline & \multicolumn{4}{|c|}{ Early } & \multicolumn{4}{|c|}{ Late } \\
\hline & $\underset{25}{\text { Over }}$ & $16-25$ & $6-15$ & $0-5$ & $1-4$ & $5-14$ & $15-24$ & $\underset{25}{\text { Over }}$ \\
\hline $\begin{array}{ll}\text { Over } 25 \mathrm{~min} \\
16-25 & 31 \\
6-15 & " 1 \\
1-5 & " 3\end{array}$ & $\begin{array}{l}25 \\
25 \\
37 \cdot 5 \\
12 \cdot 5 \\
0\end{array}$ & $\begin{array}{r}8.7 \\
4.3 \\
43.5 \\
21.7 \\
21.7\end{array}$ & $\begin{array}{r}1 \cdot 2 \\
14.6 \\
37 \cdot 8 \\
39 \cdot 0 \\
7 \cdot 3\end{array}$ & $\begin{array}{r}0.8 \\
9 \cdot 0 \\
40.7 \\
33.3 \\
16.3\end{array}$ & $\begin{array}{c}0 \\
3 \cdot 3 \\
46 \cdot 7 \\
36 \cdot 7 \\
13 \cdot 3\end{array}$ & $\begin{array}{c}0 \\
4 \cdot 7 \\
48 \cdot 8 \\
32 \cdot 6 \\
14 \cdot 0\end{array}$ & $\begin{array}{c}0 \\
0 \\
28 \cdot 6 \\
42 \cdot 9 \\
28 \cdot 9\end{array}$ & $\begin{array}{r}\mathbf{0} \\
\mathbf{0} \\
100 \\
0 \\
0\end{array}$ \\
\hline
\end{tabular}

fact $72.2 \%$ of the patients arrived early for their appointment, $2.5 \%$ coming 25 minutes or more too early. Bevan and Draper (1967) reckon that patients who arrive between five minutes early and four minutes late are punctual. If we extend this licence to our patients then $81.4 \%$ came on time or early.

Table III.-Patients Seen Without an Appointment (Expressed as Porcentages of the Total Consultations Booked and Unbooked)

\begin{tabular}{|c|c|c|c|}
\hline Total & Sex & Race* & Age Group \\
\hline $98(9 \cdot 4 \%)$ & $\begin{array}{l}\text { Male } 47(8.9 \%) \\
\text { Female } 51(9.8 \%)\end{array}$ & $\begin{array}{lll}\text { English } & 45(8.6 \%) \\
\text { Irish } & 20(8.1 \%) \\
\text { West Indian } & 15(11.4 \%) \\
\text { West African } & 9(27.3 \%)\end{array}$ & $\begin{array}{ccc}0-4 & 21 & (15 \cdot 4 \%) \\
5-14 & 5 & (3.4 \%) \\
15-44 & 50 & (9.4 \%) \\
45-64 & 17 & (9.0 \%) \\
65+ & 5 & (5.5 \%)\end{array}$ \\
\hline
\end{tabular}

* Excluding nine patients who did not come into the four groups listed.

\section{Unkept Appointments}

It is interesting that the number of patients who did not keep a booked appointment is almost the same as the number who came to the surgery without an appointment (Tables III and IV), and that by and large the age and race distribution of these two groups is identical. Our senior receptionist is of the opinion that in the main it is the same patients who miss booked appointments who, when they do come, do so without at first booking. The worst offenders are children under school age and "workers" (those aged 15-44). West Indian and West African patients also seem to find it as difficult to keep appointments as they do to arrive on time. Many explanations could be offered for these differences; each explanation might be valid.

TABLE IV.-Patients Who Did Not Keep Their Appointment (Expressed as Percentages of Those Who Booked an Appointment, Whether or Not They Kept Their Appointment)

\begin{tabular}{|c|c|c|c|}
\hline Total & Sex & Race* & Age Group \\
\hline $100(9.5 \%)$ & $\begin{array}{l}\text { Male } 42(8.0 \%) \\
\text { Female } 58(11.0 \%)\end{array}$ & $\begin{array}{llr}\text { English } & 48(9.1 \%) \\
\text { Irish } & 19(7.7 \%) \\
\text { West Indian } & 20(14.6 \%) \\
\text { West African } & 5(27.3 \%)\end{array}$ & $\begin{array}{ccc}0-4 & 22 & (16.1 \%) \\
5-14 & 3 & (3.4 \%) \\
15-44 & 52 & (9.5 \%) \\
45-64 & 16 & (8.5 \%) \\
65+ & 7 & (7.7 \%)\end{array}$ \\
\hline
\end{tabular}

- Excluding eight patients who did not come into the four groups listed.

We also asked 240 of our patients whether or not they wanted us to continue to work an appointment system: $84.2 \%$ said they wanted us to continue $; 7.7 \%$ said they would prefer us not to make appointments ; $8.1 \%$ said they did not mind what we did. These proportions are remarkably similar to those found by my brother in his practice (Carne and Dell, 1965), and by others (Fry et al., 1963 ; Dean et al., 1965 ; Stevenson, 1966).

The sample was not selected for age, sex, or race. It was merely a selection of patients living in the area. Those who did not like making appointments to see their doctor have had 
five years to change to another practice where patients can wait their turn during fixed surgery hours.

\section{Conclusion}

Several studies, already referred to, have shown that it is possible to organize an appointment system within a National Health Service general practice even where the average time for a consultation is only five minutes. In this study we have shown that the system also works well in a practice with a large proportion of immigrant patients.

The West Indian and West African immigrants are not as good timekeepers as the English and Irish patients, but their lack of punctuality is not sufficiently great to upset the smooth running of the surgery sessions.

It is our belief that the ability to see patients by appointment has been a major benefit to both patients and us. In addition to the advantages referred to by other authors (summarized by
Bevan and Draper, 1967) we are of the opinion that the making of an appointment gives "status" to the consultation. It is the aim of a supermarket to encourage "impulse buying." It is debatable whether "impulse consulting" is in the interest of anyone, notwithstanding the patients who find it difficult to tell the doctor all their problems first time.

\section{REFERBNCBS}

Bevan, J. M., and Draper, G J. (1967). Appointment Systems in General Practice. London.

Carne, J., and Dell, A. (1965). Brit. med. F., 1, 927.

Carne, S. (1962). Ibid.. 2, 1404. 1963). Practitioner, 191, 233.

1967). A Symposium on the Medical and Social Problems of the (19migrant Population in Great Britain. Royal College of General Immigrant Population in

Dean, D., Dean, I. M., Wilkinson, B. R., and McMurdo, R. (1965). Brit. med. Ұ., i, 592

Fry, J., Dillane, J. B., Fry, L., Blake, Peggy, and Fry, J. (1963). Lancet, 2, 397.

Stevenson, J. S. K. (1966). Brit. med. F., 2, 515.

\section{CONFERENCES AND MEETINGS}

\section{Medicine, Science, and Humanity-Annual Meeting of R.C.G.P.}

The Fifteenth Annual General Meeting of the Royal College of General Practitioners was held in London on 18 November. The Chairman of the Council, Dr. H. N. LevitT, said that in the year in which the College had been granted the Royal Prefix it was for the first time financially solvent. Fifteen years ago it had set out to convince other doctors, especially those in hospital and in the universities, that the general practitioner had a significant role in the future of medicine. Its views were now accepted, and general practice was recognized as a discipline in its own right. The College's next task was to establish a form of education which would raise the quality and realize the potentialities of general practice.

\section{James Mackenzie Lecture}

Giving the James Mackenzie lecture, "Lucerna Pedibus Meis," Dr. Ronald GiBSON (Winchester) emphasized two facts. Firstly, today-as in Mackenzie's time-what mattered most was the family unit. Secondly, throughout the ages the medical profession had a responsibility to society, which was becoming increasingly important today as the influence of the Church and authority declined. He asked whether anything was more likely to disturb family relationships and destroy attempts at collective responsibility than paying adolescents as much as their parents might earn. Fortunately most adolescents emerged unscathed and became useful members of society.

Where had society been found wanting ? People had not yet accepted that the failings and shortcomings of the adolescent were those of society as a whole. If people were content to perpetuate this second-rate society they were too insecure and too unstable to benefit fully from a Welfare State. The family was the medium on which the Welfare State could grow and adolescents could thrive, and the State should have a supporting and secondary role.

\section{[From a SPBCtal Correspondent]}

\section{Problems of Today}

On 19 November the College held a symposium on "Combined OperationsMedicine, Science, and Humanity." Opening the symposium, Professor Sir EDWARD WAYNE (Glasgow) said that though we had eliminated the infectious diseases we had other problems to face: the care of an ageing population; the implications of such advances as artificial insemination; and the impact of automation. Scientific advances made the ability to deal sympathetically with human beings more important than ever before.

Professor John ANDERSON (London) spoke about the changing relationship between medicine and society. The medical relationship, traditionally based on a personal contract between patient and doctor, was changing. Individual health was linked to community health, and doctors had a duty to the community as well as to their patients. Doctors' basic premises needed rethinking in this context; the demand for medical care was unlimited and they must learn to reorganize their limited resources to meet it. Computers, by helping people to think logically, could help doctors to deal with the psychological and social pressures of society.

Medical education needed new attitudes if it was to produce doctors who remained students of medicine in a rapidly changing field. The domination of the basic science departments in medical schools must give way to the teaching of community care if future doctors were to combine basic clinical skills with ability to communicate with patients and retain flexible attitudes of mind. In King's College Hospital they were trying to establish general-practitioner teaching for medical students, but were hampered by lack of money. They encouraged students who could find a general practitioner willing to take them to spend a fortnight in general practice during their undergraduate course.

\section{Research in General Practice}

Professor Sir Max Rosenheim, P.R.C.P. (London), speaking of the importance of research in general practice, said that it was needed not only to stimulate and improve morale but to cultivate the inquiring minds which good medical schools were producing. The Royal College of General Practitioners had played a very large part in encouraging research which was both operationalorganization of general practice, functions of group practices and health centres, the work of the general practitioner-and true medical research, exemplified by the work of Pickles in epidemiology. Both kinds of research needed now a combined operation in which hospitals, local authorities, social workers, statisticians, and doctors all took part, in order to get significant results. More research was needed into psychiatric disorders in the community, and he cited the work of general practitioners such as C. A. H. Watts on depression, Max Clyne on school absenteeism, and Anthony Ryle on neurosis in ordinary families as forerunners. Clinical trials of new drugs were also needed in general practice, and they must be controlled by teams which included clinical pharmacologists and sociologists if their findings were to be valid. Medical schools now acknowledged their responsibilities to the community. Educationally their task was to produce a general-purpose doctor, who after qualification would be vocationally trained for general practice as for other branches of medicine.

Professor Wilfrid Card (Glasgow), speaking on "Clinical Medicine in the Computer Age," said that the Hippocratic method was coming to an end; the private world of the individual doctor would be replaced by the public world of science. We needed a calculus of medicine, for, whereas the concept of disease was a useful fiction, a patient with signs and symptoms was the reality. A computer if fed the right data could make a diagnosis more accurately and 